\title{
Modifiable Behavioral Risk Factors Associated with Biological Risk Factors in Subjects at Risk of Type 2 Diabetes in Benin: PREDIBE Study
}

\author{
Clemence Germaine Metonnou ${ }^{{ }^{*}}$, Colette Sylvie Azandjeme ${ }^{1}$, Bio Nigan Issiako ${ }^{2}$, \\ Charles Jerome Sossa', Ghislain Emmanuel Sopoh ${ }^{3}$, Moussiliou Noël Paraïso', \\ Victoire Agueh ${ }^{1}$
}

\begin{abstract}
${ }^{1}$ Health Promotion Department, Regional Institute of Public Health, University of Abomey-Calavi, Abomey-Calavi, Benin ${ }^{2}$ Laboratory Sports Performance, Health and Evaluation, National Institute of Youth, Physical Education and Sport (INJEPS), University of Abomey-Calavi (UAC), Porto-Novo, Benin ${ }^{3}$ Environment and Health Department, Regional Institute of Public Health, University of Abomey-Calavi, Abomey-Calavi, Benin Email: ^metonnouc@yahoo.fr
\end{abstract}

How to cite this paper: Metonnou, C.G., Azandjeme, C.S., Issiako, B.N., Sossa, C.J., Sopoh, G.E., Paraïso, M.N. and Agueh, V. (2020) Modifiable Behavioral Risk Factors Associated with Biological Risk Factors in Subjects at Risk of Type 2 Diabetes in Benin: PREDIBE Study. Open Journal of Epidemiology, 10, 432-445.

https://doi.org/10.4236/ojepi.2020.104034

Received: August 26, 2020

Accepted: November 7, 2020

Published: November 10, 2020

Copyright $\odot 2020$ by author(s) and Scientific Research Publishing Inc. This work is licensed under the Creative Commons Attribution International License (CC BY 4.0).

http://creativecommons.org/licenses/by/4.0/

\begin{abstract}
Introduction: Type 2 diabetes is a major public health problem worldwide. This study aimed at identifying modifiable behavioral risk factors associated with biological factors in people at risk of type 2 diabetes which could be targeted in the design and implementation of appropriate interventions to prevent the disease. Methods: 180 subjects at risk of type 2 diabetes (aged 15 - 60 years) were identified and selected at random during a preliminary survey conducted in two groups of villages in northeastern Benin. The study took part on August 2017. Questionnaires were administered to consenting subjects; anthropometric measurements taken and blood samples withdrawn. Blood samples were subjected to biochemical testing according to standard protocols. Results: Data was obtained from 180 subjects at risk of type 2 diabetes. The average age of the subjects was $42.76 \pm 11.30$ years. Multivariate analysis showed inadequate dietary intake score, low physical activity and tobacco use as behavioral factors significantly associated with high waist circumference, high blood sugar, low HDL cholesterol, high triglyceride levels and high body fat percentage. Conclusion: There is a possible association between biological and behavioral risk factors.
\end{abstract}

\section{Keywords}

Modifiable Risk Factors, Type 2 Diabetes, Benin 


\section{Introduction}

Several reports from the International Diabetes Federation (IDF) have announced the progression of the diabetes pandemic and its threat to public health [1]. On the other hand, there is strong evidence that lifestyle-based interventions reduce the incidence or delay the onset of type 2 diabetes in high-risk individuals. A $30 \%$ to $60 \%$ decrease in the incidence of type 2 diabetes in subjects with pre-diabetes, following interventions targeting structured behavioral approaches to lifestyle changes in India has been shown [2]. Furthermore, studies have shown that diets characterized by high consumption of fruits and vegetables, whole grains, fish and poultry and by a decrease in consumption of red and processed meats, high-fat dairy products, processed foods [3] [4] and sugary drinks can reduce the risk of type 2 diabetes in the general population by $20 \%$ [5]. Smoking status and even exposure to a smoking environment are associated with an increased risk of type 2 diabetes [6]. However, moderate alcohol consumption would have a protective effect on type 2 diabetes [7]. In view of these findings, it seems appropriate to study the association between behavioral risk factors and biological risk factors for type 2 diabetes in order to better design and implement a prevention intervention in northeastern Benin.

\section{Framework and Methods}

\subsection{Study Framework}

This cross-sectional, descriptive and analytical study which took place in August 2017 as part of the "PreDiBe" project initiated by IRSP (Regional Institute of Public Health) and WDF (world Diabetes Fondation) was conducted in the municipality of Tchaourou. This municipality is located in the north-east of Benin, covers an area of approximately $7256 \mathrm{~km}^{2}$ and has a population of 222,138 inhabitants [8].

\subsection{Study Population}

A group of six villages (Tchatchou, Tékparou, Worogui Tchaourou Badékparou centre and Kinnoukpanou) in the municipality of Tchaourou was randomly selected from the 36 villages in the municipality. Study participants were consenting subjects aged 15 to 60 years, of both sexes, at risk of T2DM and have been permanently resident in the commune of Tchaourou for at least six months. These at-risk subjects were identified previously in a baseline survey using the questionnaire "Findrisc" (the investigators went from house to house in the six villages to administer Findrisc to all subjects meeting the inclusion criteria). At the end of the administration of the questionnaire, scores were calculated for each participant. A score $\geq 12$ was indicative of being at a high risk of type 2 diabetes [9]. Following the administration of the questionnaire, personne-at risk were given an appointment for venous blood samples were collected from the participants. Pregnant and breastfeeding women, individuals with medical conditions preventing questionnaire administration, taking of anthropometric 
measurements and non-consenting individuals were excluded from the study.

\subsection{Sample Size}

The number of at risk individuals for type 2 diabetes found in the six villages totaled 720 . For this study, 25\% (180) of these individuals were selected using simple random sampling method.

\subsection{Data Collection and Sample Collection}

A standardized questionnaire was administered to participants to capture data on socio-demographics, dietary habits, physical activity level, smoking status and alcohol consumption level. More so, anthropometric measurements (weight, standing height, waist circumference, fat mass percentage) as well as systolic and diastolic blood pressure readings were taken. Blood samples were taken $(4 \mathrm{ml}$ of blood in a labelled $5 \mathrm{ml}$ plain tube and $4 \mathrm{ml}$ of blood in a $5 \mathrm{ml}$ blood glucose tube) from participants in fasting state and temporarily stored in a transport box with cold accumulators and then transferred to the municipal health centre laboratory. On arrival, they were centrifuged, aliquoted into Eppendorf micro tubes and stored at $-20^{\circ} \mathrm{C}$ before being transferred to the Public Health Laboratory of the Comlan Alfred QUENUM Regional Institute of Public Health (IRSPCAQ) for biochemical/biological measurements such as fasting blood glucose, total cholesterol, HDL cholesterol, LDL cholesterol and triglycerides.

\subsection{Study Variables}

These included modifiable biological and behavioral risk factors such as: blood glucose, blood pressure, triglyceridemia, total cholesterol, LDL cholesterol, HDL cholesterol, body mass index, waist circumference, body fat percentage, dietary profile, physical activity level, alcohol and tobacco consumption status

- modifiable biological risk factors which are: blood sugar, blood pressure, triglyceridemia, blood levels of total cholesterol, LDL-cholesterol, HDL-cholesterol, body mass index, waist circumference, percentage of body fat;

- modifiable behavioural factors which are: dietary profile, level of physical activity, alcohol consumption status, tobacco consumption status.

\subsubsection{Blood Sugar Levels}

Glucose levels was determined by the glucose oxidase method in plasma at the Public Health Laboratory of the IRSP-CAQ in Ouidah in subjects at risk of type 2 diabetes, fasting for at least twelve hours. Diabetes is defined on the basis of WHO thresholds. Thus a fasting blood glucose level $>7 \mathrm{mmol} / \mathrm{L}(126 \mathrm{mg} / \mathrm{dL})$ has been considered as a case of diabetes [10].

\subsubsection{Blood Pressure}

The blood pressure was measured in a seated position after a 15-minute rest; the average of two measurements spaced 5 minutes apart will be taken [11]. The IDF criteria for screening for hypertension (hypertension), namely: a systolic blood pressure $\geq 130 \mathrm{mmHg}$ and/or a diastolic blood pressure $\geq 85 \mathrm{mmHg}$, were used 
to define cases of high blood pressure [12].

\subsubsection{Lipid Profile}

HDL-cholesterol (HDL-C), total cholesterol and LDL-cholesterol (LDL-C) was measured. The risk defining threshold values will be: for total cholesterol (TC) > $5.2 \mathrm{mmol} / \mathrm{L}$; for LDL-C $>3.37 \mathrm{mmol} / \mathrm{L}$; for HDL-C $<0.91 \mathrm{mmol} / \mathrm{L}$; and for TG on an empty stomach $\geq 1.71 \mathrm{mmol} / \mathrm{L}$ [13]. The direct laboratory assay will concern total cholesterol (TC), HDL-cholesterol (HDL-C), and triglycerides (TG). The LDL-cholesterol will be calculated per difference according to the following formula: $\mathrm{LDL}=\mathrm{CT}-[(\mathrm{HDLC})+\mathrm{TG} / 5]-[14]$.

\subsubsection{Weight}

The weight was measured on an empty stomach, with the participant wearing the minimum amount of clothing [15] and empty pockets. The scale will be calibrated every day at the beginning of each series of measurements.

\subsubsection{Size}

It was taken with a vertical tape measure in all subjects, according to the WHO procedure [16]. The subjects were standing on a flat surface with feet together. After making sure that the heels, buttocks, back and neck are in contact with the vertical support, the subject's gaze will be directed in a horizontal plane (Frankfort plane).

\subsubsection{Overweight}

The body mass index $\left(\mathrm{BMI}=\right.$ weight $/$ height $\left.^{2}\right)$ is the indicator that defined the overall obesity of the study participants. A BMI between 25 and $29.9 \mathrm{~kg} / \mathrm{m}^{2}$ defines overweight while a BMI $\geq 30 \mathrm{~kg} / \mathrm{m}^{2}$ defines obesity [17].

\subsubsection{Percentage of Body Fat}

The percentage of body fat is the index that was used to assess the proportion of adipose tissue in relation to that of muscle tissue in the subjects of the study. It was measured in the subject in light clothing and without shoes on. The percentage of fat mass is the quotient of fat mass on the total weight. A threshold of $33 \%$ for women and $25 \%$ for men defines a high percentage of fat mass according to Jackson [18].

\subsubsection{Abdominal Obesity}

The waist circumference was measured using a graduated, non-stretchable flexible tape. It was placed halfway between the last rib and the upper end of the iliac crest on the same side [19]. The thresholds of the IDF [1]: $94 \mathrm{~cm}$ in men and 80 $\mathrm{cm}$ in women, was used in order to be able to detect all persons at risk of abdominal obesity.

\subsubsection{Eating Habits}

The participants' eating habits was collected by means of a questionnaire. For each participant, the questionnaire documented the daily frequency of food consumption, the number of days per week, and then the number of weeks in a 
month, of the following ten food groups: cereals, pulses, tubers, oilseeds, dairy products, animal proteins, oils, vegetables, fruits, beverages. The questionnaire also provided information on the consumption of "local fast-food type" foods (bean, wheat, maize, peanut, cassava, fried yam and potato fritters, fried banana, etc.), "western fast-food type" foods, salt and sugar consumption habits.

\subsubsection{Level of Physical Activity}

Information on physical activity was collected through a questionnaire based on the WHO's chronic disease surveillance questionnaire. The intensity of physical activity was evaluated according to the energy expenditure induced. A distinction was made between low, moderate and high intensity activities [20]. On the basis of the weekly frequency, the average duration of activity sessions and the WHO recommendations, namely a minimum of 30 minutes per day of moderate-intensity physical activity as a means of preventing CVD [21], the subjects were classified into three groups: slightly active subjects, moderately active subjects and active subjects.

\subsubsection{Alcohol Consumption}

Information on alcohol consumption was obtained by questionnaire. The questions used were taken from the WHO's STEPwise instrument for chronic disease surveillance and adapted to the context of the study. These questions identify drinking habits (frequency, quantity), type of drink (wine, beer, distilled beverages). From the information collected, we will determine the amount of alcohol consumed per day and construct an alcohol consumption score. Standard beverage containers were used to help participants answer as accurately as possible: a bottle of beer ( $33 \mathrm{cl}$ for a small bottle or $60 \mathrm{cl}$ for a large bottle), a glass of wine $(10 \mathrm{cl})$ or a glass of distilled spirits $(4 \mathrm{cl})$. The questionnaire items identified the drinking habits (frequency, quantity) and the type of drink (local alcohol, wine, beer). The average quantity of ethanol consumed (in grams per day) was calculated on the basis of drinking frequency and the quantity of alcohol contained in the drinks ( $4.4 \%$ for beer, $11.5 \%$ for wine and $40 \%$ for local distilled alcohol). The results were grouped into three categories: zero, $0 \mathrm{~g} /$ day of alcohol per day; moderate consumption, $\leq 15 \mathrm{~g} /$ day for women and $\leq 20 \mathrm{~g} /$ day for men; alcohol abuse $>15 \mathrm{~g} /$ day for women or $>20 \mathrm{~g} /$ day for men [22] [23].

\subsubsection{Tobacco Consumption Status}

Data on tobacco consumption was collected using the questionnaire based on the WHO model [24] used in the STEPwise approach for monitoring chronic diseases. The questions identify the consumption habits of tobacco products, the number of times per day they were used and the different forms of consumption.

\subsubsection{Socio-Economic Status}

Three indicators, namely level of education, individual possessions and occupation, were used to assess the of the study subjects. A maximum score of 2 were assigned to each of these indicators. The total score (score $1+$ score $2+$ score 3 ) 
for the socio-economic le individual possessions and occupation, were used to assess the socio-economic status of the study subjects. A maximum score of 2 was assigned to each of these indicators. The total score (score $1+$ score $2+$ score 3) for the socio-economic level therefore vary from 0 to 6 . This total score was divided into three groups on the basis of terciles (low, medium and high). This score was a proxy indicator of the socio-economic level of households, usually used for demographic and health surveys [25].

\subsection{Data Quality and Validity}

The probabilistic method and the simple randomized, non-delivery technique used optimized the quality of the study results. The tools used for data collection were the questionnaire (WHO standardized tool adapted for this study), anthropometric measurements made with validated and standardized tools. In the same way, biological/biochemical measurements were carried out with standardized devices and all investigators had acquired expertise in the use of all tools. A pre-test was carried out to identify and correct shortcomings related to the questionnaire. The completeness and accuracy of the data collection tools were confirmed prior to entry and analysis.

\subsection{Statistical Analysis}

The data were analyzed using IBM SPSS Statistics 21 (IBM United States 2012). Quantitative variables were expressed as mean \pm standard deviation. Blood glucose, triglyceridemia, total cholesterol, HDL cholesterol and LDL cholesterol were expressed in grams per deciliter $(\mathrm{g} / \mathrm{L})$ and qualitative variables as percentages. Association between each biological risk factor and the behavioral risk factors considered in this study was investigated using Student t-test and correlation.

\subsection{Ethical Opinions and Authorizations}

The protocol received the approval of the Ethics Committee of the Ministry of Health of Benin.

\section{Results}

The general characteristics of the study participants are described in Table 1 . The participants' average age was $42.76 \pm 11.30$ years and $25.6 \%$ fell under the low socio-economic status category. Study participants with no education made up $84.4 \%$; while $42.8 \%$; $51.1 \%$; $48.3 \%$ and $70.6 \%$ of the subjects had low physical activity levels, high alcohol consumption rates, tobacco use and inadequate consumption scores respectively. In this population of subjects at risk for type $2 \mathrm{di}$ abetes, the mean blood glucose level was $1.14 \pm 0.09 \mathrm{~g} / \mathrm{L}$, the mean triglyceridemia was $1.51 \pm 0.16 \mathrm{~g} / \mathrm{L}$, the mean total cholesterol level was $2.10 \pm 0.35 \mathrm{~g} / \mathrm{L}$, the mean LDL cholesterol was $1.19 \pm 0.26 \mathrm{~g} / \mathrm{L}$ and the mean HDL cholesterol level was $0.30 \pm 0.09 \mathrm{~g} / \mathrm{L}$.

The glycemic profile of study participants varied with the risk factors for type 
2 diabetes (Table 2). Obese subjects were significantly more numerous in the group of subjects with impaired fasting glucose levels than those with normal blood glucose levels ( $71.4 \%$ vs. $26.5 \%)$. Less active subjects were more present in the group of subjects with blood glucose abnormalities than in the group of subjects with normal blood glucose levels (87.5.4\% vs. $42.6 \%$ ). Subjects with hypercholesterolemia and high triglyceridemic, were significantly more numerous in the group of subjects with impaired fasting glucose levels.

Table 3 showed behavioral factors associated with biological risk factors. Tobacco use, physical activity and food consumption score were significantly associated with high blood sugar, low HDL, high triglycerides, and high waist circumference.

Table 1. Characteristics of the study participants.

\begin{tabular}{|c|c|c|c|c|c|c|}
\hline \multirow[t]{2}{*}{ Characteristics } & \multicolumn{2}{|c|}{ All $(n=180)$} & \multicolumn{2}{|c|}{ Males $(n=51)$} & \multicolumn{2}{|c|}{ Women $(n=129)$} \\
\hline & $\%$ & $\begin{array}{c}\text { Mean } \pm \text { Standard } \\
\text { deviation }\end{array}$ & $\%$ & $\begin{array}{c}\text { Mean } \pm \text { Standard } \\
\text { deviation }\end{array}$ & $\%$ & $\begin{array}{c}\text { Mean } \pm \text { Standard } \\
\text { deviation }\end{array}$ \\
\hline Age (year) & & $42.76 \pm 11.30$ & & $43.23 \pm 11.37$ & & $42.58 \pm 11.31$ \\
\hline BMI $\left(\mathrm{m} / \mathrm{kg}^{2}\right)$ & & $30.77 \pm 6.14$ & & $29.85 \pm 5.44$ & & $32.22 \pm 7.53$ \\
\hline Waist circumference $(\mathrm{cm})$ & & $100.23 \pm 12.22$ & & $101.55 \pm 15.12$ & & $99 \pm 13.25$ \\
\hline Body fat (percentage) & & $30.78 \pm 11.49$ & & $29.95 \pm 9.77$ & & $32.23 \pm 13.00$ \\
\hline Blood sugar (g/L) & & $1.13 \pm 0.09$ & & $1.12 \pm 0.09$ & & $1.14 \pm 0.09$ \\
\hline Total cholesterol (g/L) & & $2.10 \pm 0.36$ & & $2.07 \pm 0.29$ & & $2.13 \pm 0.36$ \\
\hline LDL cholesterol (g/L) & & $1.18 \pm 0.26$ & & $1.18 \pm 0.25$ & & $1.18 \pm 0.26$ \\
\hline HDL Cholesterol (g/L) & & $0.30 \pm 0.09$ & & $0.29 \pm 0.08$ & & $0.31 \pm 0.10$ \\
\hline Triglycerides (g/L) & & $1.51 \pm 0.16$ & & $1.49 \pm 0.16$ & & $1.53 \pm 0.15$ \\
\hline $\mathrm{SBP}(\mathrm{mmHg})$ & & $142.00 \pm 21.71$ & & $143.00 \pm 20.78$ & & $142.00 \pm 20.02$ \\
\hline $\mathrm{DBP}(\mathrm{mmHg})$ & & $85.97 \pm 15.71$ & & $85.97 \pm 16$ & & $85.97 \pm 17$ \\
\hline \multicolumn{7}{|l|}{ Socio-economic level } \\
\hline Bottom & 25.6 & & 5.6 & & 20.0 & \\
\hline Medium & 37.2 & & 8.9 & & 28.3 & \\
\hline High & 37.0 & & 13.9 & & 23.3 & \\
\hline \multicolumn{7}{|l|}{ Education } \\
\hline None and primary & 84.4 & & 20 & & 64.4 & \\
\hline Secondary ${ }^{1 s t}$ cycle & 8.9 & & 3.4 & & 5.5 & \\
\hline Secondary ${ }^{\text {2nd }}$ cycle and University & 6.7 & & 5.0 & & 1.7 & \\
\hline \multicolumn{7}{|l|}{ Level of physical activity } \\
\hline Low & 70.6 & & 19.5 & & 51.1 & \\
\hline High & 29.4 & & 13 & & 16.4 & \\
\hline \multicolumn{7}{|l|}{ Alcohol consumption } \\
\hline None & 37.2 & & \multirow{3}{*}{$\begin{array}{c}6.1 \\
3.818 .4\end{array}$} & & 31.1 & \\
\hline Moderate & 11.7 & & & & 7.9 & \\
\hline High & 51.1 & & & & 32.7 & \\
\hline \multicolumn{7}{|l|}{ Tobacco } \\
\hline Yes & 48.3 & & 13.8 & & 34.5 & \\
\hline No & 51.7 & & 14.4 & & 37.3 & \\
\hline \multicolumn{7}{|l|}{ Food consumption score } \\
\hline Low & 72.4 & & 20.0 & & 52.7 & \\
\hline High & 27.2 & & 8.4 & & 18.8 & \\
\hline
\end{tabular}

BMI: Body mass index, SBP: Systolic blood pressure, DBP: Diastolic blood pressure. 
Table 2. Modifiable risk factors by blood glucose profile.

\begin{tabular}{|c|c|c|c|}
\hline Characteristics & $\begin{array}{c}\text { Normal blood sugar } \\
<1.10 \mathrm{~g} / \mathrm{dl} \\
(\mathrm{n}=68)\end{array}$ & $\begin{array}{c}\text { Dysglycemia } \\
1.10-1.25 \mathrm{~g} / \mathrm{dl} \\
(\mathrm{n}=112)\end{array}$ & $\mathrm{p}$ \\
\hline \multicolumn{4}{|l|}{ Body mass index $\left(\mathrm{kg} / \mathrm{m}^{2}\right)$} \\
\hline$<25$ & 26.83 & 5.10 & \multirow{3}{*}{0.001} \\
\hline $25-30$ & 50.00 & 14.28 & \\
\hline$>30$ & 23.17 & 80.62 & \\
\hline \multicolumn{4}{|l|}{ Waist circumference $(\mathrm{cm})$} \\
\hline Normal & 55.7 & 3.6 & \multirow{3}{*}{0.001} \\
\hline Overweight & 10.5 & 10.7 & \\
\hline Obesity & 33.8 & 85.7 & \\
\hline \multicolumn{4}{|l|}{$\%$ Body Fat } \\
\hline Normal & 54.4 & 19.6 & \multirow[t]{2}{*}{0.001} \\
\hline High & 45.6 & 80.4 & \\
\hline \multicolumn{4}{|l|}{ Level of physical activity } \\
\hline Low & 42.6 & 87.5 & \multirow[t]{2}{*}{0.002} \\
\hline High & 57.4 & 12.5 & \\
\hline \multicolumn{4}{|l|}{ Tobacco } \\
\hline No & 89.7 & 23.2 & \multirow[t]{2}{*}{$<0.001$} \\
\hline Yes & 10.3 & 76.8 & \\
\hline \multicolumn{4}{|l|}{ Alcohol consumption } \\
\hline No consumption & 48.5 & 30.4 & \multirow{3}{*}{0.001} \\
\hline Moderate consumption & 17.6 & 8.0 & \\
\hline High consumption & 33.9 & 61.6 & \\
\hline \multicolumn{4}{|c|}{ Health food consumption score $* *$} \\
\hline Low & 11.8 & 64.3 & \multirow[t]{2}{*}{0.001} \\
\hline High & 88.2 & 35.7 & \\
\hline \multicolumn{4}{|l|}{ Total cholestérol } \\
\hline$<2 \mathrm{~g} / \mathrm{L}$ & 75.0 & 37.5 & \multirow[t]{2}{*}{0.001} \\
\hline$>2 \mathrm{~g} / \mathrm{L}$ & 25.0 & 62.5 & \\
\hline \multicolumn{4}{|l|}{ Triglycerides } \\
\hline$<1.5 \mathrm{~g} / \mathrm{L}$ & 83.8 & 4.5 & \multirow[t]{2}{*}{0.002} \\
\hline$>1.5 \mathrm{~g} / \mathrm{L}$ & 16.2 & 95.5 & \\
\hline
\end{tabular}

** "Healthy foods" considered are foods that promote better health according to the literature (30).

Table 3. Multivariate logistic regression on risk factors.

\begin{tabular}{|c|c|c|c|c|c|c|c|c|}
\hline Variables & High blood glucose & & Low HDL-C & & High TG & & $\begin{array}{l}\text { High waist } \\
\text { circumference }\end{array}$ & \\
\hline & OR (CI 95\%) & $\mathrm{P}$ & OR (CI 95\%) & $\mathrm{P}$ & OR (CI 95\%) & $\mathrm{P}$ & OR (CI 95\%) & $\mathrm{P}$ \\
\hline Tobacco use & & 0.001 & & 0.004 & & 0.001 & & 0.003 \\
\hline No & 1 & & 1 & & 1 & & 1 & \\
\hline Yes & $6.5(2.18-9.50)$ & & $4.8(1.65-14.12)$ & & $8.4(3.34-14.42)$ & & $3.4(1.50-7.71)$ & \\
\hline $\begin{array}{l}\text { Food consumption } \\
\text { score }\end{array}$ & & 0.001 & & 0.04 & & 0.001 & & 0.04 \\
\hline High & 1 & & 1 & & 1 & & 1 & \\
\hline Low & $4.1(4.40-7.66)$ & & $3.0(1.01-7.10)$ & & $8.2(3.06-12.37)$ & & $2.3(1.02-5.32)$ & \\
\hline $\begin{array}{l}\text { Level of physical } \\
\text { activity }\end{array}$ & & 0.001 & & 0.08 & & 0.001 & & 0.001 \\
\hline Low & $7.1(4.20-9.92)$ & & $2.1(0.89-5.33)$ & & $6.5(2.54-10.12)$ & & $8.3(3.58-11.24)$ & \\
\hline
\end{tabular}

Odds Ratio were adjusted for Age, Sex, and BMI CI: 95\% Confidence Interval, HDL-C: High-Density Lipoprotein Cholesterol, TG: Triglycerides. 


\section{Discussion}

The study examined the relationship between modifiable behavioral risk factors and modifiable biological risk factors for type 2 diabetes. Several studies have shown the relationship between behavioral factors and the development of type 2 diabetes, [26] [27] [28] the particularity of this study is that it was conducted as a prelude to the implementation of a primary prevention intervention for type 2 diabetes in at-risk subjects. The results of the study showed that among subjects who were overweight and had abdominal obesity, those with impaired fasting glucose levels were significantly more numerous $(\mathrm{p}=0.01)$; (Table 1$)$. Subjects with abnormal blood glucose levels were significantly more numerous in the inactive group compared to subjects with high physical activity $(\mathrm{p}<0.001)$. Subjects with blood glucose abnormalities were significantly less numerous (35.7\%) in the group of those with a high food consumption score compared to those with a low consumption score (88.2\%). Abnormal blood glucose levels were observed more in subjects with high total cholesterol, high LDL cholesterol, hypertriglyceridemia and low HDL and this was significant (Table 2). Tobacco use, physical activity and food consumption score were significantly associated with high blood sugar, low HDL, high triglycerides, and high waist circumference (Table 3).

\subsection{Glycemic Profile of People at Risk for Type 2 Diabetes}

$62 \%$ of the subjects in this study had impaired fasting glucose level, according to the International Diabetes Federation threshold $(1.10-1.26 \mathrm{~g} / \mathrm{dl})$. This prevalence is higher than that found in the 2015 Benin StepWise national survey (6.8\%) among subjects aged 45 to 59 years [29]. A prevalence of $3.1 \%$ was reported among the general population in Kenya in 2018, [30] and the fasting blood glucose anomaly worldwide is $6.7 \%$ [31]. The value reported by the Buckley study in 2007 (40.04\%) in Ireland is closer to that reported on this study. The difference between our results and those of the 2015 Stepwise survey in Benin and those of the 2018 Kenya study could be explained by the fact that this present study considered only subjects at risk of type 2 diabetes [32]. Furthermore, this present study was conducted in an area observed to have high prevalence of diabetes (12.4\%) and fasting hyperglycemia (24.8) in 2015 [29]. The pre-diabetic phase is known as a risk factor for type 2 diabetes [33]. It is important to intervene at this critical phase through lifestyle changes to prevent progression to type 2 diabetes. In addition, the results of the study showed an association between certain behavioral risk factors and the biological risk factors for type 2 diabetes.

\subsection{Association between Behavioral and Biological Risk Factors in People at Risk for Type 2 Diabetes}

The results of this study show a highly significant association between low food consumption score and high fasting blood glucose; high triglyceridemic, high 
body fat percentage, high waist circumference and low HDL. In addition, subjects with lower physical activity are at higher risk of developing hyperglycemia, hypertriglyceridemia, high waist circumference and low HDL. Diabetes prevention studies have shown that the composition of the diet is an important factor in preventing the development of T2DM. Epidemiological studies have suggested that the risk of diabetes may be increased or decreased due to dietary factors. Dietary factors that can increase the risk of diabetes include excessive consumption of refined grains, sugary drinks, red and processed meat and alcohol, while food groups with protective effects are consumption of whole grains, vegetables, dairy products, legumes and nuts regardless of weight change [34] [35] [36] [37]. In addition, the study by Papakonstantinou and al. reported a good match between a diet and blood triglyceride levels in 2010. Indeed, this study highlighted that a low-calorie diet improves blood triglyceride levels in new diabetics [38]. This result is consistent with that of the current study in which subjects with a low dietary score also had fasting glucose abnormalities and high triglyceridemic. The results of this study showed an association between physical activity level and blood sugar, HDL cholesterol, triglyceride levels and waist circumference in people at risk for type 2 diabetes. Those with low activity levels compared to those with high physical activity levels were 10 times more likely to have high blood sugar, twice as likely to have low HDL cholesterol, 6 times more likely to have hypertriglyceridemia and 8 times more likely to have high waist circumference. These risk factors are the components of the metabolic syndrome [39]. Several studies have shown the effects of physical activity on the metabolic syndrome [40]. A study conducted in sedentary subjects aged 17 to 65 years who engaged in 20 weeks of moderate physical activity showed that the prevalence of the metabolic syndrome reduced from $16.9 \%$ to $11.8 \%$. It should also be noted that in this study, after 20 weeks of training, $43 \%$ of subjects showed a reduction in triglycerides, $16 \%$ an increase in HDL cholesterol and $28 \%$ a decrease in waist circumference [41]. Another study conducted by the Diabetes Prevention Program in the United States showed a reduction in the prevalence of metabolic syndrome after three years follow-up in subjects with glucose intolerance subjected to a low-calorie diet and 150 min of physical activity per week, the prevalence of metabolic syndrome at baseline reduced from $50 \%$ to $38 \%$ in subjects who underwent the intervention versus $53 \%$ in the placebo group [42]. These experiments clearly show a link between the level of physical activity and the components of the metabolic syndrome and indicate the value of physical activity in preventing the metabolic syndrome.

Some limitations in this study include the fact that it was only conducted in northern Benin and in an area with reported high prevalence of diabetes. Therefore, extrapolation of the results to other population groups in Benin requires some caution. Larger studies of people at risk for type 2 diabetes living in different settings will be needed to advocate for preventive measures against type 2 diabetes in the country. 


\section{Conclusion}

This study is the first to be conducted among people at risk for type 2 diabetes in a context of high diabetes prevalence in Benin. Several modifiable behavioral risk factors were found to be associated with modifiable biological risk factors. This result is of major interest in guiding lifestyle interventions for people at risk of type 2 diabetes. Further studies should be carried out in subjects at risk of type 2 diabetes in order to identify more factors which can be targeted in the design of strategies and interventions to delay or prevent progression to the onset of the disease.

\section{Acknowledgements}

The author gratefully acknowledges the staff of the Department of Health Promotion at the Regional Institute of Public Health. She would also like to extend her gratitude to the World Diabetes Foundation, the staff of the Tchaourou zonal hospital, the municipal administrative authorities and all study participants.

\section{Funding}

World Diabetes Foundation.

\section{Conflicts of Interest}

The authors declare no conflicts of interest regarding the publication of this paper.

\section{References}

[1] International Diabetes Federation (2015) Diabetes Atlas 7th Edition. The Authoritative Resource on the Global Burden of Diabetes.

[2] Ramachandran, A., Snehalatha, C., Mary, S., Mukesh, B., Bhaskar, A.D. and Vijay, V. (2006) The Indian Diabetes Prevention Programme Shows that Lifestyle Modification and Metformin Prevent Type 2 Diabetes in Asian Indian Subjects with Impaired Glucose Tolerance (IDPP-1). In: Marshall, S., Ed., Diabetologia, Springer, Berlin, 289-297. https://doi.org/10.1007/s00125-005-0097-z

[3] Asaad, G., Soria-Contreras, D., Bell, R.C. and Chan, C.B. (2016) Effectiveness of a Lifestyle Intervention in Patients with Type 2 Diabetes: The Physical Activity and Nutrition for Diabetes in Alberta (PANDA). Healthcare, 4, 73. https://doi.org/10.3390/healthcare4040073

[4] Sonomtseren, S., Sankhuu, Y., Warfel, J.D., Johannsen, D.L., Peterson, C.M. and Vandanmagsar, B. (2016) Lifestyle Modification Intervention Improves Glycemic Control in Mongolian Adults Who Are Overweight or Obese with Newly Diagnosed Type 2 Diabetes. Obesity Science \& Practice, 2, 303-308. https://doi.org/10.1002/osp4.56

[5] Esposito, K., Chiodini, P., Maiorino, M.I., Bellastelle, G., Panagiotakos, D. and Giugliano, D. (2014) Which Diet for Prevention of Type 2 Diabetes? A Meta-Analysis of Prospective Studies. In: Filetti, S., Ed., Endocrine, Springer, Berlin, 107-116. https://doi.org/10.1007/s12020-014-0264-4

[6] Kim, J.H., Noh, J., Choi, J.W. and Park, E.C. (2017) Association of Education and 
Smoking Status on Risk of Diabetes Mellitus: A Population-Based Nationwide Cross-Sectional Study. International Journal of Environmental Research and Public Health, 14, 655. https://doi.org/10.3390/ijerph14060655

[7] Baliunas, D.O., Taylor, J.B., Irving, H., Boerecke, M., Patra, J., Mohapatra, S., et al. (2009) Alcohol as a Risk Factor for Type 2 Diabetes: A Systematic Review and Meta-Analysis. Diabetes Care, 32, 2123-2132. https://doi.org/10.2337/dc09-0227

[8] Institut National de la Statistique d'Analyse et de l'Economie (2013) Recensement Général de la Population et de l'Habitation, République du Bénin.

[9] Schwarz, P.E., Li, J., Lindstrom, J. and Tuomilehto, J. (2009) Tools for Predicting the Risk of Type 2 Diabetes in Daily Practice. Hormone and Metabolic Research, 41, 86-97. https://doi.org/10.1055/s-0028-1087203

[10] World Health Organization (1999) Definition, Diagnosis and Classification of Diabetes Mellitus and Its Complications: Report of a WHO Consultation. Part 1, Diagnosis and Classification of Diabetes Mellitus. WHO, Geneva, 66 p.

[11] World Health Organization, International Diabetes Federation (2006) Definition and Diagnosis of Diabetes Mellitus and Intermediate Hyperglycaemia. Report of a WHO/IDF Consultation, WHO, Geneva.

[12] Millan, J., Pinto, X., Munoz, A., Zuniga, M., Rubies-Prat, J., Pallardo, L.F., et al. (2009) Lipoprotein Ratios: Physiological Significance and Clinical Usefulness in Cardiovascular Prevention. Vascular Health and Risk Management, 5, 757-765. https://doi.org/10.2147/VHRM.S6269

[13] Assmann, I.G., Buono, P., Daniele, A., Della Valle, E., Farinaro, G., Ferns, V., et al. (2014) Functional Foods and Cardiometabolic Diseases: International Task Force for Prevention of Cardiometabolic Diseases. Nutrition, Metabolism and Cardiovascular Diseases, 24, 1272- 1300. https://doi.org/10.1016/j.numecd.2014.10.010

[14] Cogill, B. (2003) Anthropometric Indicators Measurement Guide. FANTA, Washington DC, $9 \mathrm{p}$.

[15] Organisation Mondiale de la Santé (1995) Utilisation et interprétation de l'anthropométrie. Rapport d'un comité OMS d'experts. Série de Rapports techniques 854 .

[16] Lohman, T., Roche, A., Martorell, R., et al. (1988) Anthropometric Standardization Reference Manual. Human Kinetics Books, Champaign.

[17] World Health Organization (2000) Obesity: Preventing and Managing the Global Epidemic. WHO, Geneva.

[18] Harrison, G.B.E., Carter, J.L., Johnston, F., Lohman, T. and Pollock, M. (1988) Anthropometric Standardization Reference Manual. Anthropometric Standardization Reference Manual.

[19] Alberti, K.G., Zimmet, P. and Shaw, J. (2006) Metabolic Syndrome: A New World-Wide Definition. A Consensus Statement from the International Diabetes Federation. Diabetic Medicine, 23, 469-480. https://doi.org/10.1111/j.1464-5491.2006.01858.x

[20] Organisation Mondiale de la Santé (2003) Régime alimentaire, nutrition et prévention des maladies chroniques. Rapport d'une consultation OMS/FAO d'experts. OMS, Geneve, $180 \mathrm{p}$.

[21] Ainsworth, B.E., Haskell, W.L., Whitt, M.C., Irwin, M.L., Swartz, A.M., Strath, S.J., et al. (2000) Compendium of Physical Activities: an Update of Activity Codes and MET Intensities. Medicine \& Science in Sports \& Exercise, 32, 498-504. 
https://doi.org/10.1097/00005768-200009001-00009

[22] Organisation Mondiale de la Santé (2008) Cadre pour une politique scolaire mise en oeuvre de la stratégie de l'OMS sur l'alimentation, l'exercice physique et la santé, OMS, Genève, $48 \mathrm{p}$.

[23] Britton, K.A., Gaziano, J.M., Sesso, H.D. and Djoussé, L. (2009) Relation of Alcohol Consumption and Coronary Heart Disease in Hypertensive Male Physicians (From the Physicians' Health Study). The American Journal of Cardiology, 104, 932-935. https://doi.org/10.1016/j.amjcard.2009.05.036

[24] Castelnuovo, A.D., Costanzo, S., Giuseppe, R.D., Gaetano, G.D. and Iacoviello, L. (2009) Alcohol Consumption and Cardiovascular Risk: Mechanisms of Action and Epidemiologic Perspectives. Future Cardiology, 5, 467-477. https://doi.org/10.2217/fca.09.36

[25] World Health Organization (2017) STEPS Question-by-Question (Q-by-Q) Guide v.3.2. WHO, Geneva, 18 p.

[26] Montgomery, M.R., Gragnolati, M., Burke, K.A. and Paredes, E. (2000) Measuring Living Standards with Proxy Variables. In: Hayward, M.D., Ed., Demography, Springer, Berlin, 155-174. https://doi.org/10.2307/2648118

[27] Colberg, S.R., Fernhall, B., Regensteiner, J.G., Blissmer, B.J., Rubin, R.R., Chasan-Taber, L., et al. (2010) Exercise and Type 2 Diabetes the American College of Sports Medicine and the American Diabetes Association: Joint Position Statement Executive Summary. Diabetes Care, 33, 2692-2696.

https://doi.org/10.2337/dc10-1548

[28] Sossa, C., Delisle, H., Agueh, V., Sodjinou, R., Ntandou, G. and Makoutodé, M. (2013) Lifestyle and Dietary Factors Associated with the Evolution of Cardiometabolic Risk over Four Years in West-African Adults: The Benin Study. Journal of Obesity, 2013, Article ID: 298024. https://doi.org/10.1155/2013/298024

[29] Brown, R.E., Ridell, M.C., Macpherson, A.K., Canning, K.L. and Kuk, J.L. (2014) All-Cause and Cardiovascular Mortality Risk in US Adults with and without Type 2 Diabetes: Influence of Physical Activity, Pharmacological Treatment and Glycemic Control. Journal of Diabetes and Its Complications, 28, 311-315. https://doi.org/10.1016/j.jdiacomp.2013.06.005

[30] Programme National de Lutte contre les Maladies Non Transmissibles (2016) Rapport final de l'enquête pour la surveillance des facteurs de risque des maladies non transmissibles par l'approche z "STEPSwise" de l'OMS au Bénin. PNLMT, Cotonou, $152 \mathrm{p}$.

[31] Shukri, F.M., Mwangi, M., Kibachio, J., Hussein, A., Ndegwa, Z., Owondo, S., et al. (2018) Prevalence and Factors Associated with Pre-Diabetes and Diabetes Mellitus in Kenya: Results from a National Survey. BMC Public Health, 18, Article No. 1215. https://doi.org/10.1186/s12889-018-6053-x

[32] Lindström, J., Louheranta, A., Mannelin M., Rastas, M., Salminen, V., Eriksson, J., et al. (2013) The Finnish Diabetes Prevention Study (DPS): Lifestyle Intervention and 3-Year Results on Diet and Physical Activity. In: Marshall, S., Ed., Diabetologia, Springer, Berlin, 284-293. https://doi.org/10.1007/s00125-012-2752-5

[33] Chen, K.T., Chen, C.J., Gregg, E.W., Imperatore, G. and Narayan, K.M.V. (2003) Impaired Fasting Glucose and Risk of Diabetes in Taiwan: Follow-Up over 3 Years. Diabetes Research and Clinical Practice, 60, 177-182. https://doi.org/10.1016/S0168-8227(03)00037-8

[34] Dam, R.M.V., Rimm, E.B., Willett, M.J., Stempler, W.C. and Hu, F.B. (2002) Dietary Patterns and Risk for Type 2 Diabetes Mellitus in US Men. Annals of internal 
medicine, 136, 201-209.

https://doi.org/10.7326/0003-4819-136-3-200202050-00008

[35] Hodge, A., English, D., O’dea, K. and Giles, G. (2006) Alcohol Intake, Consumption Pattern and Beverage Type, and the Risk of Type 2 Diabetes. Diabetic Medicine, 23, 690-697. https://doi.org/10.1111/j.1464-5491.2006.01864.x

[36] Aune, D., Ursin, G. and Veierød, M.B. (2009) Meat Consumption and the Risk of Type 2 Diabetes: A Systematic Review and Meta-Analysis of Cohort Studies. In: Marshall, S., Ed., Diabetologia, Springer, Berlin, 2277-2287.

https://doi.org/10.1007/s00125-009-1481-X

[37] Wu, Y., Ding, Y., Tanaka, Y. and Zhang, Y. (2014) Risk Factors Contributing to Type 2 Diabetes and Recent Advances in the Treatment and Prevention. International Journal of Medical Sciences, 11, 1185-1200.

https://doi.org/10.7150/ijms.10001

[38] Papakonstantinou, E., Triantafillidou, D., Panagiotakos, D.B., Koutsovisilis, A., Saliaris, M., Manolis, A., et al. (2010) A High-Protein Low-Fat Diet Is More Effective in Improving Blood Pressure and Triglycerides in Calorie-Restricted Obese Individuals with Newly Diagnosed Type 2 Diabetes. European Journal of Clinical Nutrition, 64, 595-602. https://doi.org/10.1038/ejcn.2010.29

[39] Delarue, J., Allain, G. and Guillerm, S. (2006) Le syndrome métabolique. Nutrition Clinique et Métabolisme, 20, 114-117. https://doi.org/10.1016/j.nupar.2006.04.007

[40] LaMonte, M.J., Barlow, C.E., Jurca, R., Kampert, J.B., Church, T.S. and Blair, S.N. (2005) Cardiorespiratory Fitness Is Inversely Associated with the Incidence of Metabolic Syndrome: A Prospective Study of Men and Women. Circulation, 112, 505-512. https://doi.org/10.1161/CIRCULATIONAHA.104.503805

[41] Katzmarzyk, P.T., Leon, A.S., Wilmore, J.H., Skinner J.S., Rao, D.C., Rankiene, T., et al. (2003) Targeting the Metabolic Syndrome with Exercise: Evidence from the HERITAGE Family Study. Medicine and Science in Sports and Exercise, 35, 1703-1709. https://doi.org/10.1249/01.MSS.0000089337.73244.9B

[42] Orchard, T.J., Temprosa, M., Goldberg, R., Haffner, S., Ratner, R., Marcivina, S., et al. (2005) The Effect of Metformin and Intensive Lifestyle Intervention on the Metabolic Syndrome: The Diabetes Prevention Program Randomized trial. Annals of Internal Medicine, 142, 611-619.

https://doi.org/10.7326/0003-4819-142-8-200504190-00009 